\title{
Safe Motherhood Practices of Women in Urban and Rural Areas of Chitwan District, Nepal
}

\author{
Sushila Koirala, RN, MN, M-ED \\ B.P. Koirala Memorial Cancer Hospital Nursing College, Bharatpur, Chitwan
}

\begin{abstract}
Safe motherhood practices ensure all women receive the care they need to be safe and healthy throughout pregnancy and childbirth. It is one of the most important pillars for preventing maternal morbidity and mortality. A descriptive comparative study was conducted to compare the safe motherhood practices in selected VDC and Municipality of Chitwan District. The purposive sampling method was applied in which 120 respondents were married and had at least one child. Among them, 59 respondents were from Bharatpur Municipality and 61 respondents from Mangalpur VDC. Data was collected by interviewing mothers using a structured interview schedule. Descriptive statistics were used for data analysis. The results showed that the number of mothers in the rural area practicing safe motherhood is lower than the number of mothers in the urban area. The number of ANC visits/PNC visits, use of Iron tab, institutional delivery and use of extra nutritious diet or meal per day during pregnancy and after pregnancy were higher in respondents of the urban area. The main reason for not taking ANC/PNC services during their last birth was lack of knowledge and second was their poor economic conditions. This study concludes that the trend of visiting ANC services, delivery care, and PNC services properly are high in the age group 20-39 years and it is increasing with their level of education. Special awareness programmes about information regarding safe motherhood practices should be planned and launched especially targeting the women of rural areas.
\end{abstract}

Keywords: delivery, maternal mortality, pregnancy, preventive, safe motherhood

\section{INTRODUCTION}

Safe motherhood is one of the important components of reproductive health. It means ensuring that all women receive the care they need to be safe and healthy throughout pregnancy and childbirth (Chitrakar, 2010). Safe motherhood decreases maternal and infant mortality and morbidity. Although most maternal and infant deaths can be prevented through safe motherhood practices, millions of women worldwide are affected by maternal mortality and morbidity from preventable causes. Every minute of every day, somewhere in the world and most often in a developing country, a woman dies from complications related to pregnancy or childbirth. About 800 women die from pregnancy- or childbirth-related complications around the world every day. Almost all maternal deaths (99\%) occur in developing countries. More than half of these deaths occur in sub-Saharan Africa and almost one-third occur in South Asia (World Health Organization (WHO), 2015).

The risk of maternal mortality is highest for adolescent girls under 15 years old. Complications in pregnancy and childbirth are the leading cause of death among adolescent girls in most developing countries. Women in developing countries have on average many more 
pregnancies than women in developed countries, and their lifetime risk of death due to pregnancy is higher. A woman's lifetime risk of maternal death - the probability that a 15 years old woman will eventually die from a maternal cause - is 1 in 3800 in developed countries, versus 1 in 150 in developing countries (WHO, 2014).

Women die as a result of complications during and following pregnancy and childbirth. Most of these complications develop during pregnancy. Other complications may exist before pregnancy but are worsened during pregnancy. The major complications that account for $80 \%$ of all maternal deaths are severe bleeding (mostly bleeding after childbirth), infections (usually after childbirth), preeclampsia, eclampsia, unsafe abortion. Maternal health and newborn health are closely linked. Nearly three million newborn babies die every year, and an additional 2.6 million babies are stillborn (Patton et al., 2009). Pregnancy-related complications are among the leading causes of death and disability for women age 15-49 in developing countries (Safe Motherhood Initiative, 2010). Maternal mortality is a major cause of death and disability among women of reproductive age. 500,000 women die every year from complications related to childbearing. Many women get injured, some severely, from childbirth complications. Maternal mortality and morbidity adversely affect the health and welfare of children, families, and communities (Safe Motherhood Newsletter, 2013).

In Nepal, maternal health care practices are insufficient due to lack of education or low literacy rate of women especially in rural areas, poor economic status, lack of knowledge about health care practices and health facilities. Moreover, the maternal status of Nepal is highly affected by early marriage, excessive childbearing; joint family system, the value of son, and socio-economic and cultural factors. The approach of safe motherhood has defined concepts over maternity care (antenatal care, obstetric care, and postnatal care). Those factors vary from socio-economic demographic, caste/ethnicity even cultural or religious status. Nepalese society has its cultural norms and practices that play effective/vital roles in terms of maternal health management. The national RH strategy includes the following elements to make integrated health services available to all the people of Nepal. This includes family, planning safe motherhood including maternal care, delivery care, newborn care, child health prevention and management of complications of abortion, STDs, and management of infertility (National Reproductive Health Strategy, 1998).

Nepal has one of the highest rates of maternal deaths in Asia: currently 12 women die in Nepal every day either during pregnancy or childbirth and Nine out of 10 mothers deliver their babies at home without skilled birth attendants, contributing to a high level of maternal mortality (Options, 2013). The government of Nepal has begun a safe motherhood programme since the formulation of the safe motherhood policy in 1998. The goal of the National Safe Motherhood Program is to reduce maternal and neonatal morbidity and mortality and to improve maternal and neonatal health through preventive and promotional activities as well as by addressing avoidable factors that cause death during pregnancy, childbirth and the postpartum period. But the latest indicators in safe motherhood are not still improving. So, this study was conducted to compare the safe motherhood practices of women in urban and rural areas. 


\section{METHODS}

The descriptive comparative research design was used to identify the differences in safe motherhood practice between urban and rural levels. The study areas were chosen from Bharatpur Municipality and Mangalpur VDC (now Bharatpur Municipality ward no. 16) of Chitwan District. The data for this study were collected from two areas, VDC and Municipality in women of age group 15-49 years, who had at least one child. The sample size was 120 respondents, 61 from ward no 16 and 59 from municipality purposively.

To collect data, a structured interview schedule was developed as per the objective of the study. The direct personal interview method was applied with the help of a structured questionnaire to collect the information from the respondents. The household characteristics and individual information both are collected from women in reproductive age 15-49 years who have at least one child. The data were collected from January 18 to March 15, 2016.

Safe motherhood practice was defined as a practice that includes age at marriage, age at first childbirth, ANC check-up, diet, work during pregnancy, use of Iron tablet and TT immunization, place of delivery and, postnatal check-up. Regarding work, the usual period of work was defined as work that the respondents had been doing before their pregnancy period. A short period of work was defined as the work that the respondents had done for the four- or five months during the pregnancy period and similarly, no work was defined as the respondents did not do any work during the pregnancy.

After completion of fieldwork, the raw information was checked, edited, coded and entered in the computer analysis and managed by using SPSS software. Percentage distributions, frequencies and cross tables were used to manage the raw data which interprets the tables and cases, and compare the results with other variables (age at marriage, age of mother at childbirth, ANC visit, PNC service, use of iron tablet, TT vaccination, diet, work during pregnancy).

\section{RESULTS}

\section{Age at Marriage}

The majority of the respondents (75\%) reported their age at marriage was below 18 years (Table 1$)$. Very few $(0.8 \%)$ of them reported above 25 years was their age at marriage. Below 18 years was the age at marriage for the majority of the rural respondents $(83.6 \%)$. Similarly, in urban areas majority of the respondents $(66.1 \%)$ were married at the age of below 18 . The median age at marriage was found to be 17 years for both study areas.

Table 1: Age at Marriage

\begin{tabular}{|c|c|c|c|c|c|c|}
\hline \multirow{2}{*}{ Age at marriage } & \multicolumn{2}{|c|}{ Rural } & \multicolumn{2}{|c|}{ Urban } & \multicolumn{2}{|c|}{ Total } \\
\hline & No. & $\%$ & No. & $\%$ & No. & $\overline{\%}$ \\
\hline Below 18 years & 51 & 83.6 & 39 & 66.1 & 90 & 75.0 \\
\hline $18-20$ years & 6 & 9.8 & 8 & 13.6 & 14 & 11.7 \\
\hline 21-25 years & 4 & 6.6 & 11 & 18.6 & 15 & 12.5 \\
\hline Above 25 years & 0 & 0.0 & 1 & 1.7 & 1 & 0.8 \\
\hline Total & 61 & 100.0 & 59 & 100.0 & 120 & 100.0 \\
\hline
\end{tabular}




\section{Age at First Birth}

Most of the respondents in the rural area (90.2\%) gave birth to their first child below the age of 20 (Table 2). Similarly, in urban areas, the majority of the respondents gave birth to their first child at the age of below 20 and only $6.8 \%$ of the respondents of urban areas gave birth to their first child at the age of above 25 .

\section{Table 2: Age at First Birth}

\begin{tabular}{lcccccc}
\hline \multirow{2}{*}{ Age at first birth } & \multicolumn{2}{c}{ Rural } & \multicolumn{2}{c}{ Urban } & \multicolumn{2}{c}{ Total } \\
\cline { 2 - 7 } Below 20 years & No. & $\%$ & No. & $\%$ & No. & $\%$ \\
20-25 years & 55 & 90.2 & 38 & 64.4 & 93 & 77.5 \\
Above 25 Years & 6 & 9.8 & 17 & 28.8 & 23 & 19.2 \\
Total & 0 & 0.0 & 4 & 6.8 & 4 & 3.3 \\
\hline
\end{tabular}

\section{Types of Work and Food during Pregnancy}

The majority of total respondents $(60 \%)$ did short period works during pregnancy and $38.3 \%$ of them did usual period work (Table 3 ). In rural areas, $50.8 \%$ of the respondents did usual period work and another $49.2 \%$ of them did short period work. In urban areas, only onethird $(25.4 \%)$ of the respondents did usual period work and the majority $(71.2 \%)$ of them did short period worked during pregnancy. In rural areas, $60.7 \%$ of them took extra nutritious food during pregnancy and $76.3 \%$ of urban respondents took extra nutritious food during pregnancy.

Table 3: Types of Work and Food during Pregnancy

\begin{tabular}{lcccccc}
\hline Types of works & \multicolumn{2}{c}{ Rural } & \multicolumn{2}{c}{ Urban } & \multicolumn{2}{c}{ Total } \\
\cline { 2 - 7 } during pregnancy & No. & $\%$ & No. & $\%$ & No. & $\%$ \\
Usual period & 31 & 50.8 & 15 & 25.4 & 46 & 38.3 \\
Short period & 30 & 49.2 & 42 & 71.2 & 72 & 60.0 \\
No work & 0 & 0.0 & 2 & 3.4 & 2 & 1.7 \\
Total & 61 & 100.0 & 59 & 100.0 & 120 & 100.0 \\
Types of food during pregnancy & & & & & 31.7 \\
Usual food & 24 & 39.3 & 14 & 23.7 & 38 & 68.3 \\
Extra nutritious & 37 & 60.7 & 45 & 76.3 & 82 & 100.0 \\
Total & 61 & 100.0 & 59 & 100.0 & 120 & \\
\hline
\end{tabular}

\section{Time and Place for ANC Visit and the Reasons for not taking ANC Services during Pregnancy}

Out of 120 respondents, the majority (92.5\%) of them had visited for ANC service during pregnancy and almost all respondents of the urban area have visited for ANC check-ups (Table 4). Among the respondents in the rural area, 86.9\% of them had ANC visited during pregnancy. Among the rural respondents who had taken ANC services during pregnancy majority (52.8\%) of them visited ANC 1-4 times, 47.2\% visited ANC more than 5 times and the 
majority (69.8\%) of them had taken ANC services from the health post. They did not take ANC service due to the lack of knowledge and poor economic conditions. Among the respondents in urban areas, the majority (67.2\%) of them visited ANC more than 5 times. More than half (55.2\%) of them had taken ANC services from the hospital. This may be the cause of access to education and information.

Table 4: Time and Place for ANC Visit and the Reasons for not taking ANC Services during

Pregnancy

\begin{tabular}{lcccccc}
\hline ANC visited during & \multicolumn{2}{c}{ Rural } & \multicolumn{2}{c}{ Urban } & \multicolumn{2}{c}{ Total } \\
\cline { 2 - 7 } pregnancy & No. & $\%$ & No. & $\%$ & No. & $\%$ \\
Yes & 53 & 86.9 & 58 & 98.3 & 111 & 92.5 \\
No & 8 & 13.1 & 1 & 1.7 & 9 & 7.5 \\
Total & 61 & 100.0 & 59 & 100.0 & 120 & 100.0 \\
Times ANC visit & & & & & & \\
1-4 times & 28 & 52.8 & 19 & 32.8 & 47 & 42.3 \\
5 times and above & 25 & 47.2 & 39 & 67.2 & 64 & 57.7 \\
Total & 53 & 100.0 & 58 & 100.0 & 111 & 100.0 \\
Visiting places for ANC & & & & & & \\
Hospital & 11 & 20.8 & 32 & 55.2 & 43 & 38.7 \\
Private clinic & 5 & 9.4 & 18 & 31.0 & 23 & 20.7 \\
Health post & 37 & 69.8 & 8 & 13.8 & 45 & 40.5 \\
Total & 53 & 100.0 & 58 & 100.0 & 111 & 100.0 \\
Reasons for not taking ANC & & & & & \\
Poor economic & 2 & 25.0 & 0 & 0.0 & 2 & 22.2 \\
conditions & & & & & & \\
\hline Lack of knowledge & 6 & 75.0 & 1 & 100.0 & 7 & 77.8 \\
\hline \begin{tabular}{l} 
Total \\
\hline
\end{tabular} & 8 & 100.0 & 1 & 100.0 & 9 & 100.0 \\
\hline
\end{tabular}

\section{Level of Education and Visited time for ANC}

Timing for ANC visits is strongly related to the mother's level of education. In rural areas, it is found that the majority (54.5\%) of the respondents having primary education visited for ANC 1-4 times (Table 5). Similarly, $60 \%$ and $40 \%$ of the respondents having lower-secondary education visited for ANC 1-4 times and 5 times and above respectively. All the respondents had secondary education and above visited for ANC 5 times and above. Similarly, in urban areas, all the respondents having higher education and above visited for ANC 5 times and above 


\section{Table 5: Level of Education and Visited time for ANC}

\begin{tabular}{lcccccc}
\hline \multirow{2}{*}{$\begin{array}{l}\text { Level of } \\
\text { education }\end{array}$} & \multicolumn{3}{c}{ Rural } & \multicolumn{4}{c}{ Urban } \\
\cline { 2 - 7 } & $\begin{array}{c}1-4 \text { times No. } \\
(\%)\end{array}$ & $\begin{array}{c}5 \text { times and } \\
\text { above } \\
\text { No. }(\%)\end{array}$ & Total No. & $\begin{array}{c}1-4 \text { times No. } \\
(\%)\end{array}$ & $\begin{array}{c}5 \text { times and } \\
\text { above No. } \\
(\%)\end{array}$ & Total No. \\
Primary & $6(54.5)$ & $5(45.5)$ & 11 & $2(40.0)$ & $3(60.0)$ & 5 \\
$\begin{array}{l}\text { Lower- } \\
\text { secondary }\end{array}$ & $6(60.0)$ & $4(40.0)$ & 10 & $3(25.0)$ & $7(75.0)$ & 12 \\
$\begin{array}{l}\text { Secondary } \\
\text { Higher }\end{array}$ & - & $4(100.0)$ & 4 & $4(40.0)$ & $6(60.0)$ & 10 \\
secondary & - & $5(100.0)$ & 5 & - & $7(100.0)$ & 7 \\
$\begin{array}{l}\text { Graduate } \\
\text { Post } \\
\text { graduate }\end{array}$ & - & $1(100.0)$ & 1 & - & $4(100.0)$ & 4 \\
Total & - & $1(100.0)$ & 1 & - & $4(100.0)$ & 4 \\
\hline
\end{tabular}

\section{Iron Tablets and Tetanus Vaccines taken at the Last Birth}

In urban areas, the majority of the respondents (70.5\%) had taken the iron tab and $85.2 \%$ of the respondents from the same area had taken tetanus vaccines at the last birth (Table 6). Similarly, in rural areas, only $62.7 \%$ of the respondents had taken iron tablets and $86.4 \%$ of the respondents from the same area had taken tetanus vaccines at the last birth.

Table 6: Iron Tablets and Tetanus Vaccines taken at the Last Birth

\begin{tabular}{lcccccc}
\hline Did you take & \multicolumn{2}{c}{ Rural } & \multicolumn{2}{c}{ Urban } & \multicolumn{2}{c}{ Total } \\
\cline { 2 - 7 } iron tab? & No. & $\%$ & No. & $\%$ & No. & $\%$ \\
Yes & 37 & 62.7 & 43 & 70.5 & 80 & 66.7 \\
No & 22 & 37.3 & 18 & 29.5 & 40 & 33.3 \\
Total & 59 & 100.0 & 61 & 100.0 & 120 & 100.0 \\
Did you take tetanus vaccines? & & & & & \\
Yes & 51 & 86.4 & 52 & 85.2 & 103 & 85.8 \\
No & 8 & 13.6 & 9 & 14.8 & 17 & 14.2 \\
Total & 59 & 100.0 & 61 & 100.0 & 120 & 100.0 \\
\hline
\end{tabular}

\section{Place of Delivery at Last Birth}

In rural areas, the majority (54.1\%) of them reported that the hospital was their place of delivery at last birth followed by $26.2 \%$ of them who reported home was the place of delivery at last birth (Table 7). Nearly one-fifth of them reported health-post was the place of delivery at last birth. In urban respondents, the majority (69.5\%) reported that hospital was the place of delivery at the last birth followed by $27.1 \%$ of them who reported home was the place of delivery at the last birth. Only $3.4 \%$ of them reported health-post as their place of delivery at last birth 
Table 7: Place of Delivery at Last Birth

\begin{tabular}{lcccccc}
\hline Place of delivery & \multicolumn{2}{c}{ Rural } & \multicolumn{2}{c}{ Urban } & \multicolumn{2}{c}{ Total } \\
\cline { 2 - 7 } at last birth & No. & $\%$ & No. & $\%$ & No. & $\%$ \\
Home & 16 & 26.2 & 16 & 27.1 & 32 & 26.7 \\
Hospital & 33 & 54.1 & 41 & 69.5 & 74 & 61.7 \\
Health-post & 12 & 19.7 & 2 & 3.4 & 14 & 11.6 \\
Total & 61 & 100.0 & 59 & 100.0 & 120 & 100.0 \\
\hline
\end{tabular}

\section{Time for PNC Visit}

The below table reveals that $77 \%$ of the rural respondents had taken PNC services while almost (93.2\%) all of the urban respondents took PNC services. In rural areas, who had taken PNC services, nearly similar percent (48.9\% and 46.8\%) of them had taken PNC services two times and once after their last delivery respectively. Similarly, among the urban respondents, the majority (43.6\%) of the respondents had taken PNC services 2 times.

Table 8: Time for PNC Visit

\begin{tabular}{lcccccc}
\hline PNC Visit during & \multicolumn{2}{c}{ Rural } & \multicolumn{2}{c}{ Urban } & \multicolumn{2}{c}{ Total } \\
\cline { 2 - 7 } pregnancy? & No. & $\%$ & No. & $\%$ & No. & $\%$ \\
Yes & 47 & 77.0 & 55 & 93.2 & 102 & 85.0 \\
No & 14 & 23.0 & 4 & 6.8 & 18 & 15.0 \\
Total & 61 & 100.0 & 59 & 100.0 & 120 & 100.0 \\
How many times PNC visit? & & & & & \\
One & 22 & 46.8 & 19 & 34.5 & 41 & 40.2 \\
Two & 23 & 48.9 & 24 & 43.6 & 47 & 46.1 \\
Three & 2 & 4.3 & 9 & 16.4 & 11 & 10.8 \\
Four & 0 & 0.0 & 2 & 3.6 & 2 & 2.0 \\
Five & 0 & 0.0 & 1 & 1.8 & 1 & 1.0 \\
Total & 47 & 100.0 & 55 & 100.0 & 102 & 100.0 \\
\hline
\end{tabular}

\section{Reasons for not taking PNC Services}

In urban areas, $50 \%$ of the respondents reported that they are not taking PNC services because of lack of knowledge, poor economic condition (25\%), and lack of family support (25\%). Likewise in rural areas, the majority of the respondents are not taking PNC services due to lack of knowledge (42.9\%) followed by poor economic conditions $(28.6 \%)$ and lack of family support (21.4\%) respectively (Table 9).

Table 9: Reasons for not taking PNC Services

\begin{tabular}{lcccccc}
\hline Reasons for not taking PNC & \multicolumn{2}{c}{ Rural } & \multicolumn{2}{c}{ Urban } & \multicolumn{2}{c}{ Total } \\
\cline { 2 - 7 } services & No. & $\%$ & No. & $\%$ & No. & $\%$ \\
Poor economic conditions & 4 & 28.6 & 1 & 25.0 & 5 & 27.8 \\
Lack of family support & 3 & 21.4 & 1 & 25.0 & 4 & 22.2 \\
\hline
\end{tabular}




\begin{tabular}{lcccccc}
\hline Lack of Kn Wledge & 6 & 42.9 & 2 & 50.0 & 8 & 44.4 \\
Others & 1 & 7.1 & 0 & 0.0 & 1 & 5.6 \\
Total & 14 & 100.0 & 4 & 100.0 & 18 & 100.0 \\
\hline
\end{tabular}

Table 10 shows that all of the rural respondents having secondary level and above education had visited for PNC services after their last birth. In urban areas, almost all the respondents from different educational levels had visited for PNC services at their last birth except the secondary level.

\section{Table 10: Level of Education and PNC Visit}

\begin{tabular}{lcccccc}
\hline $\begin{array}{l}\text { Level of } \\
\text { education }\end{array}$ & \multicolumn{3}{c}{ Rural } & \multicolumn{3}{c}{ Urban } \\
\cline { 2 - 7 } & $\begin{array}{c}\text { Yes } \\
\text { No. }(\%)\end{array}$ & $\begin{array}{c}\text { No } \\
\text { No. (\%) }\end{array}$ & Total No. & $\begin{array}{c}\text { Yes } \\
\text { No. }(\%)\end{array}$ & $\begin{array}{c}\text { PNC visit } \\
\text { No. }(\%)\end{array}$ & Total No. \\
Primary & $10(90.9)$ & $1(9.1)$ & 11 & 100.0 & - & 5 \\
$\begin{array}{l}\text { Lower- } \\
\text { secondary }\end{array}$ & $9(90.0)$ & $1(10.0)$ & 10 & $12(100.0)$ & - & 12 \\
$\begin{array}{l}\text { Secondary } \\
\text { Higher }\end{array}$ & $4(100.0)$ & - & 4 & $8(80.0)$ & $2(20.0)$ & 10 \\
secondary & $5(100.0)$ & - & 5 & $7(100.0)$ & - & 7 \\
Graduate & $1(100.0)$ & - & 1 & $4(100.0)$ & - & 4 \\
Post graduate & $1(100.0)$ & - & 1 & $4(100.0)$ & - & 4 \\
Total & 93.8 & 6.2 & 32 & 95.2 & 4.8 & 42 \\
\hline
\end{tabular}

\section{DISCUSSION}

The purpose of this study was to compare the safe motherhood practice of women between urban and rural levels. More than four-fifth (83.6\%) of the rural respondents and twothird (66\%) of the urban respondents got married at the age of below 18 years. Nearly $7 \%$ of the rural respondents and $18.6 \%$ of urban respondents got married at the age between $20-25$ years. No rural respondents got married at the age of above 25 while very few $(1.7 \%)$ of urban respondents got married at the age of above 25 . The median age at marriage was 17 years for both groups of respondents. The latest data of NDHS, 2016 shows that the median age at marriage 17.9.4 years. This finding is similar to the result of the study of India, conducted by Dhagavkar et al. (2013) on Knowledge and Attitude about Safe Motherhood Practices among Pregnant Women shows that $67.1 \%$ of participants are married before the age of 20 years. Among the rural respondents, $90.2 \%$ and $9.8 \%$ of them gave birth to their first child at the age of below 20 years and $20-25$ years, respectively while among the urban respondents $64.4 \%$ and $28.8 \%$ gave birth to their first child at the age of below 20 years and 20-25 years respectively. This result is similar to the study on Safe Motherhood Practices among Muslim Women in Taple VDC of Gorkha District conducted by Lamichhane (2009) which shows that majority of women (54\%) had their first childbirth at the age of below 20 years. In Nepal, National data shows that $17 \%$ of women age 15-19 have begun childbearing (MOH\&P, 2016). 
Regarding the ANC visit, $47.2 \%$ of rural and $67.2 \%$ of urban respondents received ANC 5 times and more. $62.7 \%$ of the rural respondents and $70.5 \%$ of the urban respondents have taken iron tablets during their pregnancy. This result is far contrary to the study on antenatal care and birth preparedness practices among mothers in Mahottari district, Nepal done by Sharma and Mishra (2011) showed that only 3\% of women received ANC 4 times and more. But most of the mothers took the iron tablet (97\%). There are still more mothers who are out of the utilisation of ANC services. In this study, who did not take ANC visits during their last pregnancy, the majority (75\%) of them reported that it was due to the lack of knowledge, and $25 \%$ reported due to their poor economic conditions.

During pregnancy, mothers need extra rest and a nutritious diet for meeting the requirement of self and growing fetus. Nearly half (49.2\%) of the rural respondents and $71.2 \%$ of urban respondents did short period work during the last pregnancy period and $60.7 \%$ of rural respondents and $76.3 \%$ of urban respondents took extra-nutritious food during their last pregnancy period. Similarly, mothers need an extra nutritious diet during the postnatal period to maintain their health and wellbeing. The majority of respondents $(82.5 \%)$ in both areas had taken four meals per day.

Institutional delivery is an important effort to reduce the health risk of both mother and baby and in reducing maternal and child mortality and mortality. More than two-third (69.5\%) of the urban respondents and more than half of rural respondents delivered their last baby in hospitals. This cleared that still more than one-third of respondents had home delivery. This finding is contrary to the finding of the study conducted by Prasad (2012) on Safe Motherhood Practice in Dalit Community in Bara District, Nepal which found that only 30\% of respondents had institutional delivery. In this study, more than three-fourth of rural respondents and the majority (93\%) of the urban respondents received PNC service. The respondents who did not get a PNC visit reported that the main reasons for not getting a PNC visit were lack of knowledge (44.4\%), poor economic condition (27.8\%), and lack of family support (22.2\%). This study also found out that the timing of ANC and PNC visits are strongly related to the level of education.

\section{CONCLUSION}

Based on the major findings of this study, it can be concluded that Nepalese women in rural areas get marriage and give their first childbirth at an early age. They are still out of access to use safe motherhood services due to lack of awareness/education, poor socio-economic condition, and lack of family support. The trend of utilizing ANC and PNC services is also increasing with their level of education.

\section{REFERENCES}

Baral, O. P., \& Vashisth, K. (2014). Goal, strategies and programme of safe motherhood in Nepal. Academic Voices: A Multidisciplinary Journal, 3(1), 19-23. Retrieved from https://doi.org/10.3126/av.v3i1.9981. 
Bhatta, B.N. (2008). Public health awareness building in the field of safe motherhood. Journal of Nepal Health Research Council, 6(13), 69-73. doi: 10.3126/jnhrc. v6i2.2187

Bharatpur Municipality, (2072). Yearly city development plan. Fiscal Year 2015.

Chitrakar, G. (2010). Family health and reproductive health. Makalu publication, Kathmandu.

Dhagavkar, P.S., Dalal, A. \& Angolkar, M. (2013). Knowledge and attitude about safe motherhood practices among pregnant women in Belagavi, Karnataka.

Khan.S. (2010). Reproductive health of Muslim women in Nepal: A case study of Maleth VDC, Saptari district. A Report Submitted to Social Inclusion Research Fund, Assistance Programme, Lalitpur.

Lamichhane, M. (2009). Safe motherhood practices among Muslim women in Taple VDC of Gorkha district. Journal of Nepal Health Research Council, Retrieved from http: //library.nhrc.gov.np:8080/nhrc/handle/123456789/50 on 21/4/2016.

Ministry of Health. (1998). National reproductive health strategy. Kathmandu: The Author.

Ministry of Health and Population (2016). Nepal Demographic and Health Survey. Population Division, Ministry of Health and Population: New ERA.

Options (2013). Retrieved from http://www.options.co.uk/our-programmes/safe-motherhoodnepal on $1 / 2 / 2016$.

Patton GC, Coffey C, Sawyer SM, Viner RM, Haller DM, Bose K, Vos T, Ferguson J, Mathers CD (2009). Global patterns of mortality in young people: a systematic analysis of population health data. Lancet, 374:881-892. Accessed on 3/3/2015 from https://www.who.int/teams/sexual-and-reproductive-health-and-research

Prasad, S. (2012). Safe motherhood Practice in Dalit Community. Academic Voices: A Multidisciplinary Journal, 3(1). 63-68.

Safe Motherhood Newsletter. (Oct. 2012). Retrieved from http://bixbycenter.ucsf.edu/research/safe_motherhood.html on 1/2/2013.

Safe Motherhood Initiative. (2010). Retrieved Safe Motherhood Policy, Family Health Division, Department of Health Services, Ministry of Health, Government of Nepal. (1998).

Retrieved from http://www.adranepal.org/pdf/publication/SMIP booklet.pdf on 1/1/2013. From http://www.safemotherhood.org/ on 3/2/2013.

Sharma, R. \& Mishra, S.K. (2011). Antenatal care (ANC) and birth preparedness practices (BPP) among mothers in Mahottari district, Nepal.

WHO. (2014). Maternal Mortality. Retrieved from

https://apps.who.int/iris/bitstream/handle/10665/112318/WHO_RHR_14.06_eng. pdf on 13/12/2016 